\title{
Changes in breaststroke swimming performances in national and international athletes competing between 1994 and 2011 -a comparison with freestyle swimming performances
}

\author{
Mathias Wolfrum ${ }^{1,2}$, Christoph Alexander Rüst ${ }^{1}$, Thomas Rosemann ${ }^{1}$, Romuald Lepers ${ }^{3}$ and Beat Knechtle ${ }^{1,4^{*}}$
}

\begin{abstract}
Background: The purpose of the present study was to analyse potential changes in performance of elite breaststroke swimmers competing at national and international level and to compare to elite freestyle swimming performance.

Methods: Temporal trends in performance of elite breaststroke swimmers were analysed from records of the Swiss Swimming Federation and the FINA (Fédération Internationale de Natation) World Swimming Championships during the 1994-2011 period. Swimming speeds of elite female and male breaststroke swimmers competing in $50 \mathrm{~m}, 100 \mathrm{~m}$, and $200 \mathrm{~m}$ were examined using linear regression, non-linear regression and analysis of variance. Results of breaststroke swimmers were compared to results of freestyle swimmers.

Results: Swimming speed in both strokes improved significantly $(p<0.0001-0.025)$ over time for both sexes, with the exception of $50 \mathrm{~m}$ breaststroke for FINA men. Sex differences in swimming speed increased significantly over time for Swiss freestyle swimmers $(p<0.0001)$, but not for FINA swimmers for freestyle, while the sex difference remained stable for Swiss and FINA breaststroke swimmers. The sex differences in swimming speed decreased significantly $(p<0.0001)$ with increasing race distance.

Conclusions: The present study showed that elite male and female swimmers competing during the 1994-2011 period at national and international level improved their swimming speed in both breaststroke and freestyle. The sex difference in freestyle swimming speed consistently increased in athletes competing at national level, whereas it remained unchanged in athletes competing at international level. Future studies should investigate temporal trends for recent time in other strokes, to determine whether this improvement is a generalized phenomenon.
\end{abstract}

Keywords: Swimming speed, Sex-related difference, Gender difference, Men, Women

\section{Background}

Improved understanding of performance by top athletes, including long-term changes and sex-related differences, can help athletes and coaches to estimate performance limits, to choose appropriate training protocols, and to set realistic goals. During the past 30 years, several studies investigated human limits in various sports such as running

\footnotetext{
* Correspondence: beat.knechtle@hispeed.ch

${ }^{1}$ Institute of General Practice and for Health Services Research, University of

Zurich, Zurich, Switzerland

${ }^{4}$ Gesundheitszentrum St. Gallen, Vadianstrasse 26, 9001 St. Gallen,

Switzerland

Full list of author information is available at the end of the article
}

[1-3], track and field [4], tennis [4], and swimming [3]. However, the results were inconsistent. For example, Whipp and Ward [5] predicted that there would be no limits to human performance in running, and women would eventually run faster than men, while Cheuvront et al. [2] concluded that running performances by both men and women had already reached a plateau. Similarly, Nevill et al. [3] suggested that freestyle swimming performance had reached the limits of human capability. World record speeds improved significantly during the 1960s and 1970s, but levelled off early in the $21^{\text {st }}$ century [3]. This conclusion was further supported by Seiler et al. [6] and 
Johnson et al. [7]. However, temporal trends have not been examined in other strokes, and in fact, new world records in breaststroke and freestyle swimming were set by both men and women during the 2012 Olympic Games [8], suggesting that swimming performance has not reached its limit.

For swimmers, changes in performance over time have mainly been investigated in freestyle swimming [3,9-11]. Nevill et al. reported that the $10 \%$ faster performance in men compared to women in various freestyle swimming events remained unchanged during the last 60 years [3]. However, it is not known whether or not this is also true for breaststroke swimming. Differences between freestyle and breaststroke do exist in terms of technique, energy cost and stroke length [12]. It has been shown that freestyle is the most economic stroke, followed by backstroke, butterfly and breaststroke [13].

The changes in swimming performance have been investigated for freestyle swimmers competing at international top level $[3,9,10]$. Little data is known for changes in freestyle swimming performance across years for swimmers competing at national level [11] and no data exist for changes in swimming performance over time for other strokes such as breaststroke [14]. Differences in performance between athletes competing at international and national level are related to differences in the energetic and biomechanical profiles of these athletes [15-18]. Considering breaststroke, Seifert et al. [19] reported differences in the elbow-knee continuous relative phase in breaststroke swimmers of different performance levels. Furthermore, recent studies reported greater sex-related differences in swimming speed for freestyle than for breaststroke for swimmers at national level, but not for swimmers competing at international level [14]. This finding might be attributed to the biomechanics of the two swimming styles [20,21]. However, there is now comprehensive data about the temporal trend over recent years for the sex differences in breaststroke and freestyle swimming.

The purpose of the present study was to investigate the changes in breaststroke swimming performance in athletes competing at both national and international level and to compare breaststroke swimming performance to freestyle swimming performance. We therefore analyzed changes in freestyle and breaststroke performance of the annual top ten Swiss swimmers (i.e. national level) and the eight finalists in the Fédération Internationale de Natation (FINA) World Championships (i.e. international level) during the 1994-2011 period for $50 \mathrm{~m}, 100 \mathrm{~m}$, and $200 \mathrm{~m}$. The aims of the present study were to investigate $(i)$ potential changes in breaststroke swimming performance across years in national and international athletes and to compare to potential changes in freestyle swimming performance, $(i i)$ differences in swimming performance between national and international athletes and (iii) differences in swimming performance between women and men. We hypothesized that $(i)$ performance in breaststroke swimmers would improve over time, (ii) national athletes would compete slower that international athletes and (iii) men would be faster than women for all distances with a constant sex difference in swimming performance.

\section{Methods}

\section{Ethics}

All procedures used in the study were approved by the Institutional Review Board of Kanton St. Gallen, Switzerland with a waiver of the requirement for informed consent of the participants given the fact that the study involved the analysis of publicly available data.

\section{Subjects and design}

Race times on long courses for the annual top ten men and women in breaststroke and freestyle swimming recorded in the Swiss high score list between 1994 and 2011 were obtained per civil year from the website of the Swiss Swimming Federation [22]. The Swiss Swimming Federation records only the annual best swimming performance for each athlete, so no Swiss athlete was included more than once in the same year. Race times for the eight female and male finalists competing on international level in breaststroke and freestyle in the FINA (Fédération Internationale de Natation) World Swimming Championships between 1994 and 2011 were obtained from the website of the FINA [23]. Race times for athletes competing on national level were available annually for swimmers for both breaststroke and freestyle and all distances (i.e. $50 \mathrm{~m}, 100 \mathrm{~m}$, and $200 \mathrm{~m}$ ). For FINA finalists, race times were available from the World Championships in Rome (1994), Perth (1998) Fukuoka (2001), Barcelona (2003), Montreal (2005), Melbourne (2007), Rome (2009) and Shanghai (2011). The $50 \mathrm{~m}$ breaststroke was held for the first time in the 2001 World Championships.

\section{Methodology}

Since races in breaststroke swimming were held for $50 \mathrm{~m}, 100 \mathrm{~m}$ and $200 \mathrm{~m}$ but freestyle races for $50 \mathrm{~m}$, $100 \mathrm{~m}, 200 \mathrm{~m}, 400 \mathrm{~m}, 800 \mathrm{~m}$ and 1,500 m, we analysed freestyle swimming races only for $50 \mathrm{~m}, 100 \mathrm{~m}$, and $200 \mathrm{~m}$ to compare with breaststroke swimming results. To allow a comparison of swimming performance for different styles and distances, race times were transformed to swimming speed by dividing race distance by time. To determine temporal trends, we compared the average annual swimming speed for each stroke and race distance, by the top ten Swiss men and top ten Swiss women, and by the eight men and eight women competing in the FINA finals. To analyse the maximum overall 
swimming performance, we averaged the fastest ten swimming speeds in each stroke for four groups: Swiss women, Swiss men, FINA women, and FINA men. Sexrelated differences were calculated using the equation [(women swimming speed) - (men swimming speed)]/ (men swimming speed) $\times 100$. The calculation was performed for pairs of equally placed athletes during each year, e.g., the fastest women and men, the second fastest women and men, etc. The absolute value of the sexrelated difference for each pair was used to calculate the annual mean and standard deviation.

\section{Statistical analyses}

Prior to statistical analyses, each data set was tested for normal distribution and homogeneity of variances. Normal distribution was tested using a D'Agostino and Pearson omnibus normality test. Homogeneity of variances was tested using a Levene's test, in cases with two groups, and with a Bartlett's test, in cases with more than two groups. A potential change in swimming speed across years was investigated using regression analyses. Since the change in sex difference in endurance is assumed to be non-linear [24], we additionally calculated the non-linear regression model that fits the data best. For swimmers at national level, polynomial regressions from $2^{\text {nd }}$ to $17^{\text {th }}$ degree were calculated; for swimmers at international level, polynomial regressions from $2^{\text {nd }}$ to $7^{\text {th }}$ degree were calculated. Additionally, LOWESS (i.e. locally weighted scatterplot smoothing) and 64 further standard models were used. We compared the best-fit non-linear models to the linear models using Akaike's Information Criteria (AIC) and F-test in order to show which model (i.e. linear versus non-linear) would be the most appropriate to explain the trend of the data. One-way analysis of variance (ANOVA) with subsequent Tukey-Kramer post-hoc tests were used to compare data for multiple groups. A two-way ANOVA with a Bonferroni post-hoc test was used to determine the significance of interactive effects of swimming style and sex on performance. Significance of all statistical tests was accepted at $p<0.05$. Statistical analyses were performed using IBM SPSS Statistics (Version 19 and 20, IBM SPSS, Chicago, IL, USA) and GraphPad Prism (Version 5 and 6.01, GraphPad Software, La Jolla, CA, USA). Data are reported in the text and figures as mean \pm standard deviation (SD).

\section{Results}

\section{Changes in breaststroke and freestyle swimming speed across the years}

Figure 1,2,3 and 4 present the changes in swimming speeds for breaststroke (Figure 1) and freestyle (Figure 2) in Swiss swimmers and for breaststroke (Figure 3) and freestyle (Figure 4) in FINA swimmers for $50 \mathrm{~m}$ (Panels A), $100 \mathrm{~m}$ (Panels B) and $200 \mathrm{~m}$ (Panels C). Swimming speed
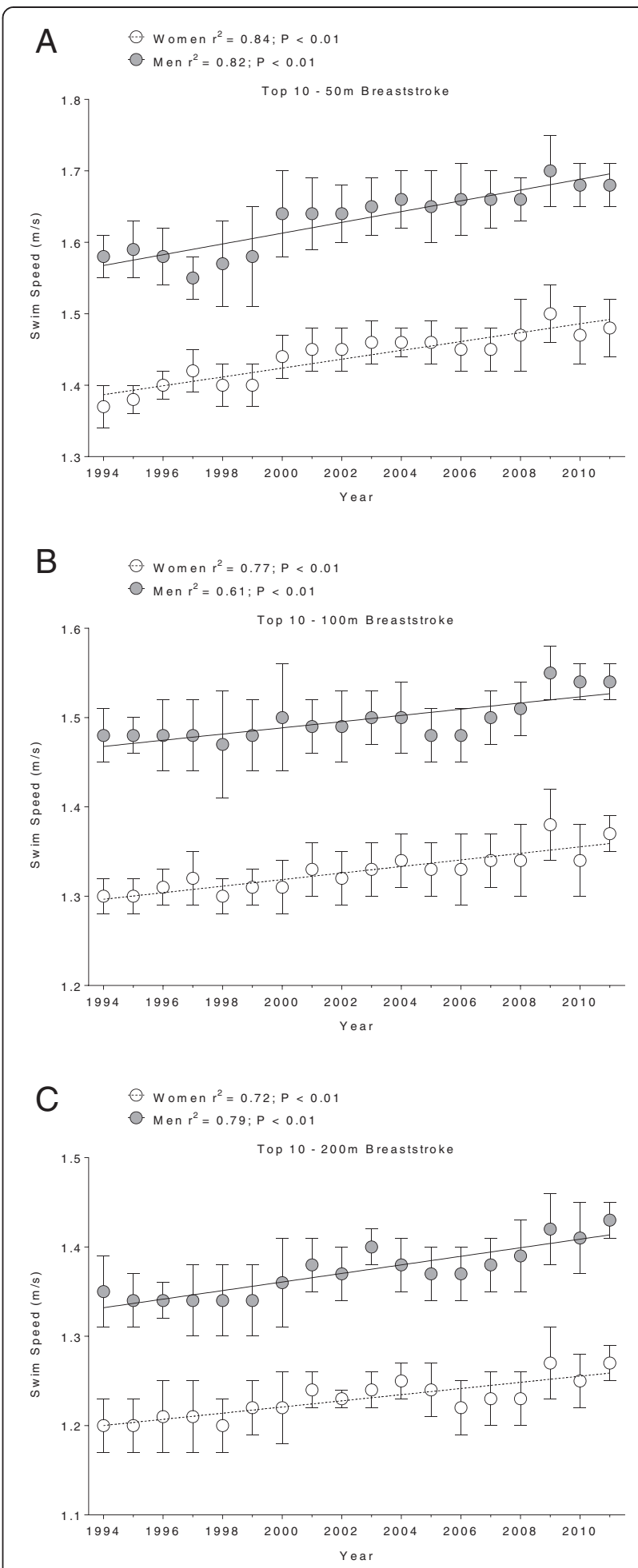

Figure 1 Swimming speeds of Swiss top ten breaststroke swimmers for $50 \mathrm{~m}$ (Panel A), $100 \mathrm{~m}$ (Panel B) and $200 \mathrm{~m}$ (Panel C). Results are presented as mean \pm SD. 


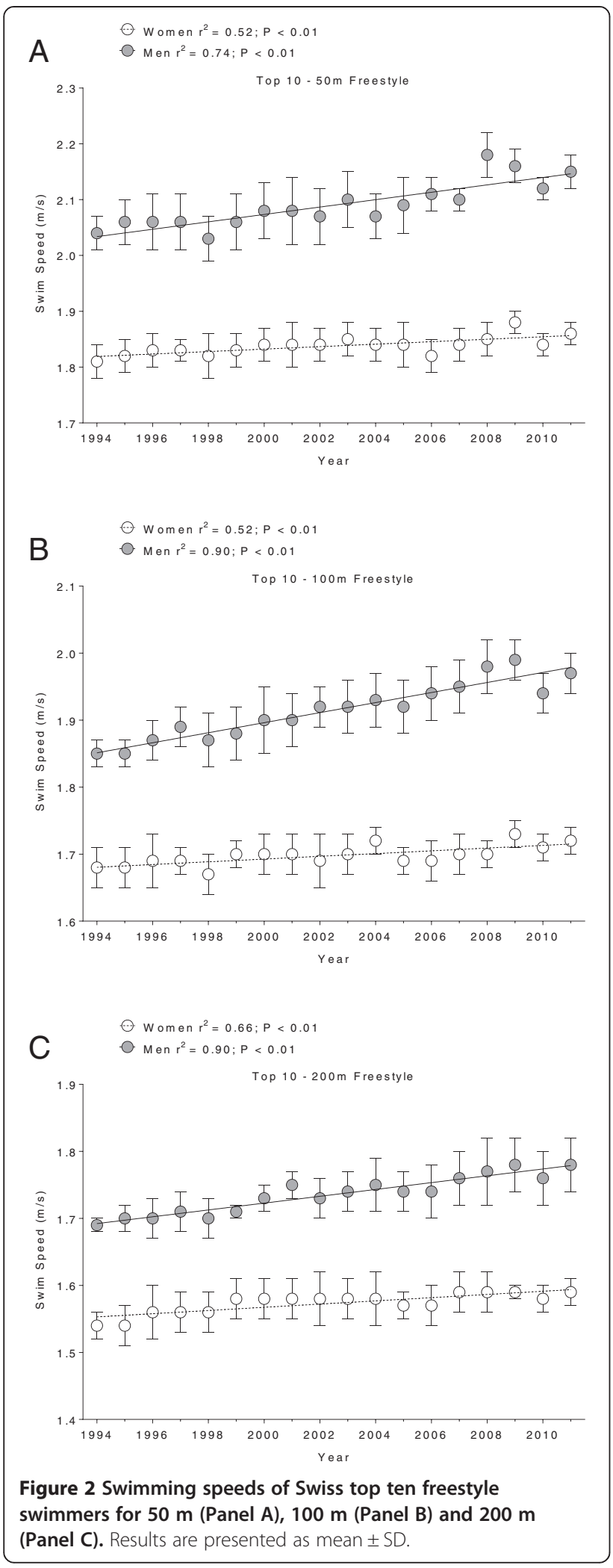

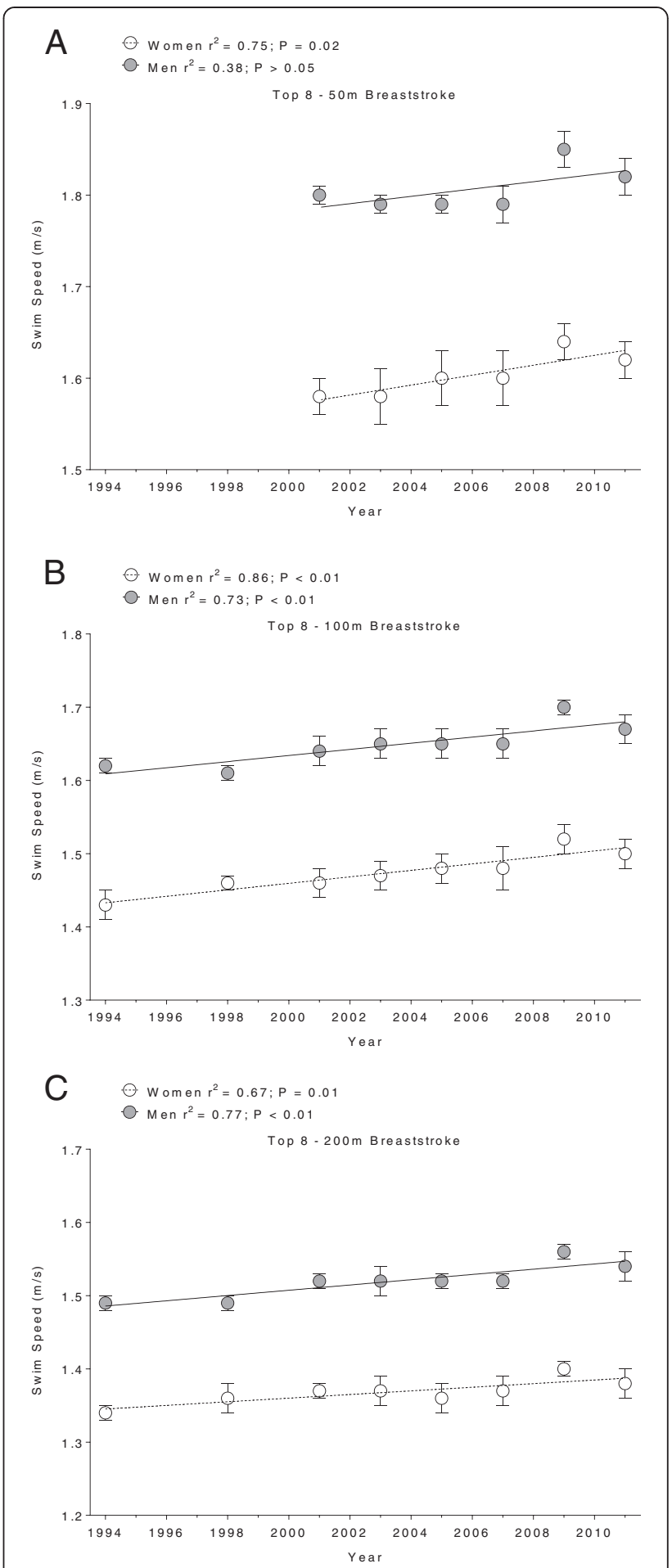

Figure 3 Swimming speeds of breaststroke FINA finalists for $50 \mathrm{~m}$ (Panel A), $100 \mathrm{~m}$ (Panel B) and $200 \mathrm{~m}$ (Panel C). Results are presented as mean $\pm \mathrm{SD}$. 

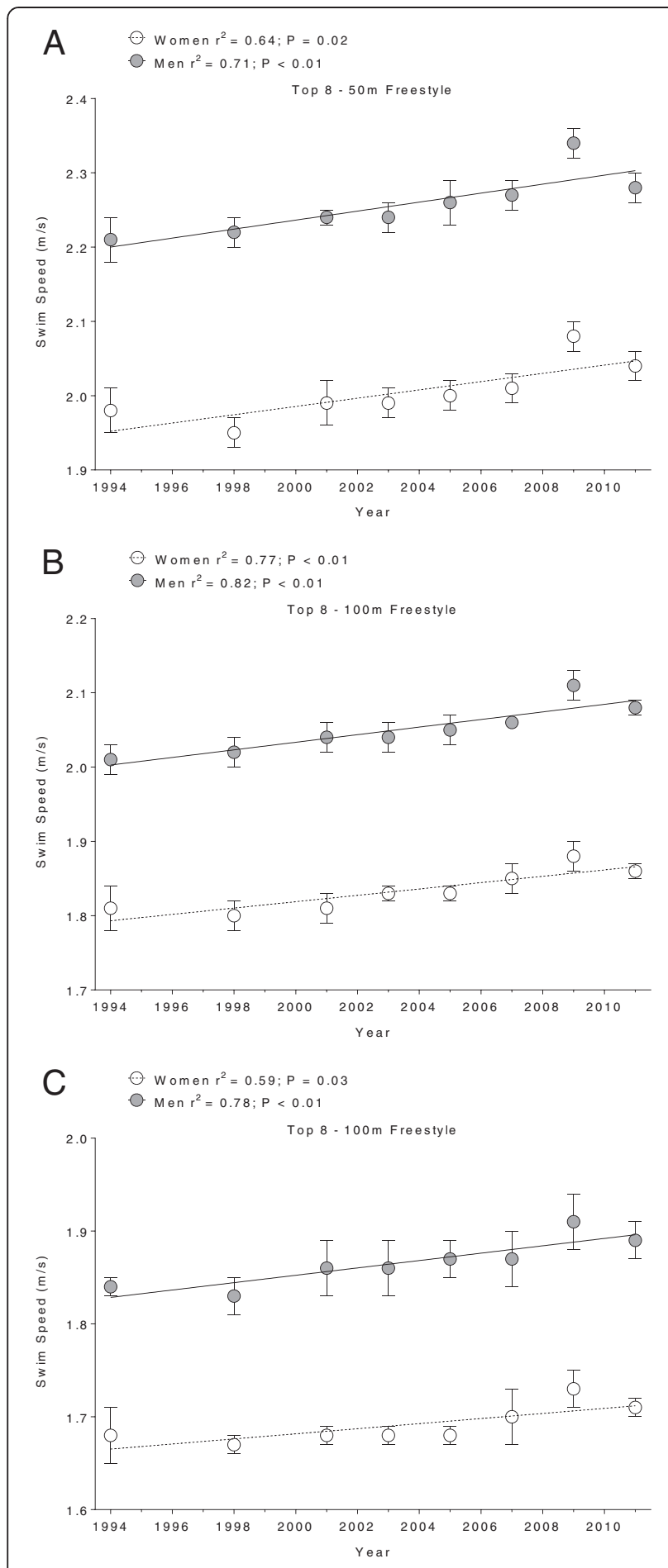

Figure 4 Swimming speeds of freestyle FINA finalists for $50 \mathrm{~m}$ (Panel A), $100 \mathrm{~m}$ (Panel B) and $200 \mathrm{~m}$ (Panel C). Results are presented as mean \pm SD.

increased linearly for Swiss swimmers in breaststroke (Table 1) and freestyle (Table 2). In FINA finalists, swimming speed increased also linearly in breaststroke (Table 3) and freestyle (Table 4), with the exception of male FINA swimmers in the $50 \mathrm{~m}$ breaststroke (Figure 3A).

In breaststroke, male Swiss swimmers increased their swimming speed by $0.008 \mathrm{~m} \cdot \mathrm{s}^{-1}, 0.004 \mathrm{~m} \cdot \mathrm{s}^{-1}$, and $0.005 \mathrm{~m} \cdot \mathrm{s}^{-1}$ per annum in $50 \mathrm{~m}, 100 \mathrm{~m}$, and $200 \mathrm{~m}$, respectively, and female swimmers by $0.006 \mathrm{~m} \cdot \mathrm{s}^{-1}$, $0.004 \mathrm{~m} \cdot \mathrm{s}^{-1}, 0.004 \mathrm{~m} \cdot \mathrm{s}^{-1}$ per annum, respectively. Male FINA swimmers increased swimming speed by $0.004 \mathrm{~m} \cdot \mathrm{s}^{-1}$ per annum over $100 \mathrm{~m}$ and $200 \mathrm{~m}$, respectively, and female swimmers by $0.005 \mathrm{~m} \cdot \mathrm{s}^{-1}, 0.004 \mathrm{~m} \cdot \mathrm{s}^{-1}, 0.003 \mathrm{~m} \cdot \mathrm{s}^{-1}$ per annum in $50 \mathrm{~m}, 100 \mathrm{~m}$, and $200 \mathrm{~m}$, respectively. In freestyle, male Swiss swimmers increased swimming speed by $0.007 \mathrm{~m} \cdot \mathrm{s}^{-1}, 0.008 \mathrm{~m} \cdot \mathrm{s}^{-1}$, and $0.005 \mathrm{~m} \cdot \mathrm{s}^{-1}$ per annum in $50 \mathrm{~m}, 100 \mathrm{~m}$, and $200 \mathrm{~m}$, respectively, and female swimmers by $0.002 \mathrm{~m} \cdot \mathrm{s}^{-1}$ per annum for all distances. Male FINA swimmers increased swimming speed by $0.006 \mathrm{~m} \cdot \mathrm{s}^{-1}, 0.005 \mathrm{~m} \cdot \mathrm{s}^{-1}$, and $0.004 \mathrm{~m} \cdot \mathrm{s}^{-1}$ per annum in $50 \mathrm{~m}, 100 \mathrm{~m}$, and $200 \mathrm{~m}$, respectively, and female swimmers by $0.006 \mathrm{~m} \cdot \mathrm{s}^{-1}, 0.004 \mathrm{~m} \cdot \mathrm{s}^{-1}$, and $0.003 \mathrm{~m} \cdot \mathrm{s}^{-1}$ per annum, respectively.

\section{Sex differences in breaststroke and freestyle swimming speed}

Men swam consistently faster than women for both strokes and all distances. In Swiss swimmers, swimming speed in breaststroke showed no changes across years (Figure 5 and Table 5). In freestyle, however, the sex difference in swimming speed increased linearly (Table 6) for all distances (Figure 6). In FINA finalists, the sex differences in swimming speed showed no significant trends over time (Table 6) for breaststroke (Figure 7) and for freestyle (Figure 8). Sex differences in both breaststroke and freestyle performance decreased significantly $(p<0.0001)$ with increasing race distance for both Swiss (Figure 9) and FINA swimmers (Figure 10) (i.e. for breaststroke at national level $50 \mathrm{~m} \mathrm{11.8 \% ,}$

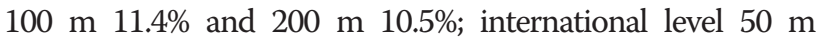




level 50 m 11.3\%, 100 m 10.6\%, 200 m 9.4\%, respectively).

\section{Interaction between style and sex}

Based on the fastest breaststroke and freestyle swimmers, swimming style and sex had a significant interactive effect on swimming speed for both Swiss ( $\mathrm{F}=15.13$, $\mathrm{Dfn}=1, \mathrm{DFd}=2156, p=0.0001)$ and FINA athletes $(\mathrm{F}=6.77, \mathrm{Dfn}=1, \mathrm{DFd}=732, p=0.0094)$ (Table 7). In Swiss swimmers, style accounted for $61.9 \%$ of the total variance of race time $(\mathrm{F}=5753.7, \mathrm{Dfn}=1, \mathrm{DFd}=732$, $p<0.0001)$ and sex for $14.7 \%$ of total variance $(\mathrm{F}=1365.6$, $\mathrm{Dfn}=1, \mathrm{DFd}=2156, p<0.0001)$, while the interaction accounted for $0.16 \%(\mathrm{~F}=15.1, \mathrm{Dfn}=1, \mathrm{DFd}=2156$, $p=0.0001)$. In the FINA swimmers, style accounted for $59.5 \%$ of the total variance of race time $(\mathrm{F}=1691.3, \mathrm{Dfn}=1$, $\mathrm{DFd}=732, p<0.0001)$, sex accounted for $14.5 \%(\mathrm{~F}=412.2$, 
Table 1 Comparison of linear and non-linear regression analysis of changes in swimming speed for female and male breast stroke swimmers at national level across years to determine which model is the best

\begin{tabular}{|c|c|c|c|c|c|c|c|c|c|}
\hline & $\begin{array}{l}\text { Kind of } \\
\text { regression }\end{array}$ & $\begin{array}{l}\text { Sum of } \\
\text { Squares }\end{array}$ & DOF & AICC & $\begin{array}{l}\text { Best regression } \\
\text { AIC-Test }\end{array}$ & $\begin{array}{l}\text { Best regression } \\
\text { F-Test }\end{array}$ & Delta & Probability & Likelihood \\
\hline $50 \mathrm{~m}$ breaststroke & polynomial & 0.0035 & 12 & -138.34 & linear & linear & 2.80 & 0.19 & $80.3 \%$ \\
\hline male Swiss swimmers & linear & 0.0062 & 16 & -141.15 & & & & & \\
\hline $100 \mathrm{~m}$ breaststroke & polynomial & 0.0009 & 0 & -144.16 & linear & undetermined & 5.72 & 0.054 & $94.6 \%$ \\
\hline male Swiss swimmers & linear & 0.0038 & 16 & -149.88 & & & & & \\
\hline $200 \mathrm{~m}$ breaststroke & polynomial & 0.0011 & 0 & -139.69 & linear & undetermined & 13.48 & 0.0011 & $99.88 \%$ \\
\hline male Swiss swimmers & linear & 0.0032 & 16 & -153.17 & & & & & \\
\hline $50 \mathrm{~m}$ breaststroke & polynomial & 0.0011 & 0 & -140.12 & linear & undetermined & 6.62 & 0.035 & $96.5 \%$ \\
\hline female Swiss swimmers & linear & 0.0045 & 16 & -146.74 & & & & & \\
\hline $100 \mathrm{~m}$ breaststroke & polynomial & 0.0018 & 0 & -131.76 & linear & undetermined & 29.91 & $3.19 e^{-07}$ & $100 \%$ \\
\hline female Swiss swimmers & linear & 0.0019 & 16 & -161.67 & & & & & \\
\hline $200 \mathrm{~m}$ breaststroke & polynomial & 0.0014 & 0 & -135.81 & linear & undetermined & 22.41 & $1.35 e^{-05}$ & $99.99 \%$ \\
\hline female Swiss swimmers & linear & 0.0024 & 16 & -158.22 & & & & & \\
\hline
\end{tabular}

For all distances, the changes in swimming speed were linear.

$\mathrm{Dfn}=1, \quad \mathrm{DFd}=732, \quad p<0.0001)$, and the interaction accounted for $0.24 \%(\mathrm{~F}=6.8, \mathrm{Dfn}=1, \mathrm{DFd}=732, p=0.009)$.

\section{Discussion}

The present study examined temporal changes in breaststroke swimming speed for top Swiss and FINA finalists and compared to freestyle swimming speed. The results showed that $(i)$ swimming speed increased for both national and international swimmers during the 1994-2011 period for both women and men with the exception for male FINA swimmers in $50 \mathrm{~m}$ breaststroke, (ii) the sex difference in swimming speed did not change significantly over time except for Swiss freestyle swimmers and (iii) the sex-related difference in swimming speed consistently decreased with increasing race distance from $50 \mathrm{~m}$ to $200 \mathrm{~m}$ for both freestyle and breaststroke.

\section{Temporal changes in breaststroke and freestyle} swimming speed

The increased swimming speed of women and men in freestyle and breaststroke swimming during the 1994-2011 period as well as the new world records during the 2012 Olympic Games [8] are partly attributable to technological advances. Deeper deck-level pools, more effective antiwave lane ropes, and improved swimming suits reducing drag, improving buoyancy, and enhancing body compression, contributed to the enhanced swimming performance $[3,25]$. Full-body, polyurethane, technical swimsuits were

Table 2 Comparison of linear and non-linear regression analysis of changes in swimming speed for female and male freestyle swimmers at national level across years to determine which model is the best

\begin{tabular}{|c|c|c|c|c|c|c|c|c|c|}
\hline & $\begin{array}{l}\text { Kind of } \\
\text { regression }\end{array}$ & $\begin{array}{l}\text { Sum of } \\
\text { Squares }\end{array}$ & DOF & AICC & $\begin{array}{l}\text { Best regression } \\
\text { AIC-Test }\end{array}$ & $\begin{array}{l}\text { Best regression } \\
\text { F-Test }\end{array}$ & Delta & Probability & Likelihood \\
\hline $50 \mathrm{~m}$ freestyle & polynomial & 0.0067 & 0 & -108.11 & linear & undetermined & 29.06 & $4.87 e^{-07}$ & $100 \%$ \\
\hline male Swiss swimmers & linear & 0.0077 & 16 & -137.18 & & & & & \\
\hline 100 m freestyle & polynomial & 0.0002 & 2 & -45.86 & linear & linear & 21.05 & $2.67 e^{-05}$ & $99.99 \%$ \\
\hline male Swiss swimmers & linear & 0.0013 & 6 & -66.92 & & & & & \\
\hline 200 m freestyle & polynomial & 0.0015 & 0 & -134.90 & linear & linear & 32.22 & $1.005 e^{-07}$ & $100 \%$ \\
\hline male Swiss swimmers & linear & 0.0014 & 16 & -167.13 & & & & & \\
\hline 50 m freestyle & polynomial & 0.0016 & 0 & -132.88 & linear & undetermined & 27.20 & $1.23 e^{-06}$ & $99.99 \%$ \\
\hline female Swiss swimmers & linear & 0.0021 & 16 & -160.08 & & & & & \\
\hline 100 m freestyle & polynomial & 0.0027 & 0 & -124.34 & linear & undetermined & 28.91 & $5.26 e^{-07}$ & $99.99 \%$ \\
\hline female Swiss swimmers & linear & 0.0031 & 16 & -153.25 & & & & & \\
\hline 200 m freestyle & polynomial & 0.0006 & 0 & -152.27 & linear & undetermined & 14.68 & 0.00064 & $99.93 \%$ \\
\hline female Swiss swimmers & linear & 0.0014 & 16 & -166.95 & & & & & \\
\hline
\end{tabular}

For all distances, the changes were linear. 
Table 3 Comparison of linear and non-linear regression analysis of changes in swimming speed for female and male breast stroke swimmers at international level across years to determine which model is the best

\begin{tabular}{|c|c|c|c|c|c|c|c|c|c|}
\hline & $\begin{array}{l}\text { Kind of } \\
\text { regression }\end{array}$ & $\begin{array}{l}\text { Sum of } \\
\text { Squares }\end{array}$ & DOF & AICC & $\begin{array}{l}\text { Best regression } \\
\text { AIC-Test }\end{array}$ & $\begin{array}{l}\text { Best regression } \\
\text { F-Test }\end{array}$ & Delta & Probability & Likelihood \\
\hline $50 \mathrm{~m}$ breaststroke & polynomial & 0.00042 & 1 & -9.35 & linear & linear & 35.83 & $1.65 e^{-08}$ & $100 \%$ \\
\hline male FINA finalists & linear & 0.00190 & 4 & -45.19 & & & & & \\
\hline $100 \mathrm{~m}$ breaststroke & polynomial & 0.00035 & 2 & -40.28 & linear & linear & 23.83 & $6.66 e^{-06}$ & $99.99 \%$ \\
\hline male FINA finalists & linear & 0.00180 & 6 & -64.12 & & & & & \\
\hline $200 \mathrm{~m}$ breaststroke & polynomial & 0.00014 & 2 & -47.16 & linear & linear & 23.19 & $9.18 e^{-06}$ & $99.99 \%$ \\
\hline male FINA finalists & linear & 0.00086 & 6 & -70.35 & & & & & \\
\hline $50 \mathrm{~m}$ breaststroke & polynomial & 0.00027 & 0 & -49.89 & linear & undetermined & 1.51 & 0.31 & $68.04 \%$ \\
\hline female FINA finalists & linear & 0.00069 & 4 & -51.41 & & & & & \\
\hline $100 \mathrm{~m}$ breaststroke & polynomial & 0.00034 & 2 & -40.31 & linear & linear & 30.66 & $2.19 e^{-07}$ & $100 \%$ \\
\hline female FINA finalists & linear & 0.00080 & 6 & -70.97 & & & & & \\
\hline 200 m breaststroke & polynomial & $8.76 e^{-05}$ & 2 & -51.37 & linear & linear & 18.04 & 0.00012 & $99.98 \%$ \\
\hline female FINA finalists & linear & 0.00097 & 6 & -69.41 & & & & & \\
\hline
\end{tabular}

For all distances, the changes were linear.

most probably an important contributor to the unprecedented run of broken records from 1990 to 2009 [26]. A full-body suit improves performance by $3.2 \pm 2.4 \%$ and reduces drag by $6.2 \pm 7.9 \%$ for distances from $25 \mathrm{~m}$ to $800 \mathrm{~m}$ leading to a reduction of energy costs [27]. Indeed, FINA's release of new rules in 2010 limiting the types of technical swimsuits that could be worn by athletes was followed by a downward trend in performance [26]. However, since 2010, there were still world records in $50 \mathrm{~m}$ pools achieved. Especially, world records in breaststroke swimming were improved. For women, Katie Ledecky improved the world records in $800 \mathrm{~m}$ and 1,500 $\mathrm{m}$ freestyle in 2013, Missy Frankling in 2012 for 200 m backstroke, Ruta Meilutyte in 2013 for $50 \mathrm{~m}$ and $100 \mathrm{~m}$ breaststroke and Rikke Møller
Pederson for $200 \mathrm{~m}$ breaststroke. For butterfly, Dana Vollmer improved the world record for $100 \mathrm{~m}$ in 2012. For men, Sun Yang improved the 1,500 m freestyle world record in 2012, Cameron van der Burgh in 2012 the world record in $100 \mathrm{~m}$ breaststroke, Akihiro Yamaguchi also in 2012 for $200 \mathrm{~m}$ breaststroke and Ryan Lochte in 2011 for $200 \mathrm{~m}$ individual medley [8].

In addition to technological advances, swimming speed during the 1994-2011 period could have been affected by changes in anthropometric and physiological characteristics [28], improvements in training [29], competition psychology [30,31], and sports nutrition [32], as well as increased access to the sport by a larger number of athletes [4]. A study of 6-17 year-old children during

Table 4 Comparison of linear and non-linear regression analysis of changes in swimming speed for female and male freestyle swimmers at international level across years to determine which model is the best

\begin{tabular}{|c|c|c|c|c|c|c|c|c|c|}
\hline & $\begin{array}{l}\text { Kind of } \\
\text { regression }\end{array}$ & $\begin{array}{l}\text { Sum of } \\
\text { Squares }\end{array}$ & DOF & AICC & $\begin{array}{l}\text { Best regression } \\
\text { AIC-Test }\end{array}$ & $\begin{array}{l}\text { Best regression } \\
\text { F-Test }\end{array}$ & Delta & Probability & Likelihood \\
\hline $50 \mathrm{~m}$ freestyle & polynomial & 0.00061 & 2 & -35.82 & linear & linear & 23.53 & $7.76 e^{-06}$ & $99.99 \%$ \\
\hline male FINA finalists & linear & 0.00340 & 6 & -59.35 & & & & & \\
\hline $100 \mathrm{~m}$ freestyle & polynomial & 0.00017 & 2 & -45.86 & linear & linear & 32.22 & $1.005 e^{-07}$ & $100 \%$ \\
\hline male FINA finalists & linear & 0.00130 & 6 & -66.92 & & & & & \\
\hline $200 \mathrm{~m}$ freestyle & polynomial & 0.00020 & 2 & -44.73 & linear & linear & 23.55 & $7.69 e^{-06}$ & $99.99 \%$ \\
\hline male FINA finalists & linear & 0.00110 & 6 & -68.28 & & & & & \\
\hline $50 \mathrm{~m}$ freestyle & polynomial & 0.00039 & 2 & -39.26 & linear & linear & 18.46 & $9.76 e^{-05}$ & $99.99 \%$ \\
\hline female FINA finalists & linear & 0.00420 & 6 & -57.73 & & & & & \\
\hline $100 \mathrm{~m}$ freestyle & polynomial & 0.00019 & 2 & -44.78 & linear & linear & 22.05 & $1.62 e^{-05}$ & $99.99 \%$ \\
\hline female FINA finalists & linear & 0.00130 & 6 & -66.84 & & & & & \\
\hline $200 \mathrm{~m}$ freestyle & polynomial & $1.58 e^{-05}$ & 2 & -65.03 & linear & polynomial & 1.24 & 0.34 & $65.08 \%$ \\
\hline female FINA finalists & linear & 0.00140 & 6 & -66.27 & & & & & \\
\hline
\end{tabular}

The changes were linear for all distances. 



Figure 5 Sex differences of Swiss top ten breaststroke swimmers for $50 \mathrm{~m}$ (Panel A), $100 \mathrm{~m}$ (Panel B) and $200 \mathrm{~m}$ (Panel C). Results are presented as mean \pm SD.

$20^{\text {th }}$ century found an increase of $1-2 \mathrm{~cm}$ in body height and $0.5-1.5 \mathrm{~kg}$ in body weight per decade [33], a trend which could have led to the improved performances observed in our study. Charles and Bejan [34] observed that the mean body height of champion swimmers in $100 \mathrm{~m}$ freestyle increased by $11.4 \mathrm{~cm}$ since 1912, and predicted that the fastest athletes would become heavier and taller in future. If available, anthropometric data for Swiss and FINA competitors during the 1994-2011 period could be used to test these assumptions. Due to the linear increase in swimming speed for both national and international swimmers for both breaststroke and freestyle, we may assume that the limits of performance have not reached yet a limit with the exception of the $50 \mathrm{~m}$ breaststroke in FINA finalists where the limit of performance may be been reached. However, the period of 1994-2011 might be too short to define whether the change was really linear. Nevill et al. [3] investigated the changes in swimming speeds in $100 \mathrm{~m}, 200 \mathrm{~m}$, and $400 \mathrm{~m}$ freestyle world records from 1957 to 2006 and found that a flattened ' $\mathrm{S}$-shaped curve' logistic curve best described the changes.

\section{Sex differences in breaststroke and freestyle swimming}

Results of previous studies reporting that the difference between men and women's world freestyle records remained stable during the past 60 years $[3,4,26]$, were confirmed by results of the present study showing that sex-related differences in breaststroke - and in freestyle swimming by FINA athletes - remained relatively constant over time. The temporal increase in the sex-related difference in freestyle performance by Swiss swimmers is difficult to explain. Different levels of freestyle swimming performance by the variations of velocity, stroke rate, and especially stroke length were found in $100 \mathrm{~m}$ freestyle for male swimmers of differing skills (i.e. national versus international level) [35]. Additionally, international swimmers are able to maintain a higher energetic and biomechanical capacity than national swimmers [15] and high-speed swimmers have a higher and more stable stroke length and index of coordination than low-speed swimmers [36].

Sex-related differences in performance are largely explained by sex-specific differences in body dimensions, swimming speed, buoyancy, stroke mechanics, stroke length, starts and turn time, basic and specific endurance, anaerobic power and capacity, muscle power, and flexibility [3,37-39]. Young male swimmers have a higher speed fluctuation, active drag, power needed to overcome and technique drag index than young female swimmers [40]. Male freestyle swimmers have also a greater stroke length than female swimmers [36]. Male athletes exhibit greater left ventricular end-diastolic volume than female athletes, resulting in higher stroke volume at rest and during exercise, and higher cardiac output in absolute and relative terms [41]. Men also have $5-10 \%$ higher haemoglobin content, which increases oxygen carrying capacity at sub-maximal oxygen uptake levels. These factors lead to greater peak aerobic 
Table 5 Comparison of linear and non-linear regression analysis of changes in sex difference for freestyle and breaststroke swimmers at national level across years to determine which model is the best

\begin{tabular}{|c|c|c|c|c|c|c|c|c|c|}
\hline & $\begin{array}{l}\text { Kind of } \\
\text { regression }\end{array}$ & $\begin{array}{l}\text { Sum of } \\
\text { Squares }\end{array}$ & DOF & AICC & $\begin{array}{l}\text { Best regression } \\
\text { AIC-Test }\end{array}$ & $\begin{array}{l}\text { Best regression } \\
\text { F-Test }\end{array}$ & Delta & Probability & Likelihood \\
\hline $50 \mathrm{~m}$ breaststroke & polynomial & 10.02 & 0 & 23.45 & linear & undetermined & 21.71 & $1.92 e^{-5}$ & $99.99 \%$ \\
\hline Swiss swimmers & linear & 17.49 & 16 & 1.73 & & & & & \\
\hline $100 \mathrm{~m}$ breaststroke & polynomial & 2.78 & 0 & 0.40 & linear & linear & 13.75 & 0.0010 & $99.89 \%$ \\
\hline Swiss swimmers & linear & 7.56 & 16 & -13.35 & & & & & \\
\hline $200 \mathrm{~m}$ breaststroke & polynomial & 3.80 & 0 & 6.03 & linear & undetermined & 22.42 & $1.34 e^{-5}$ & $99.99 \%$ \\
\hline Swiss swimmers & linear & 6.38 & 18 & -16.39 & & & & & \\
\hline $50 \mathrm{~m}$ freestyle & polynomial & 7.20 & 0 & 17.51 & linear & undetermined & 24.94 & $3.83 e^{-6}$ & $99.99 \%$ \\
\hline Swiss swimmers & linear & 10.51 & 16 & -7.42 & & & & & \\
\hline $100 \mathrm{~m}$ freestyle & polynomial & 3.93 & 13 & -16.30 & linear & linear & 1.30 & 0.34 & $65.7 \%$ \\
\hline Swiss swimmers & linear & 5.97 & 16 & -17.61 & & & & & \\
\hline $200 \mathrm{~m}$ freestyle & polynomial & 1.90 & 0 & -6.42 & linear & undetermined & 18.32 & 0.00010 & $99.98 \%$ \\
\hline Swiss swimmers & linear & 4.01 & 16 & -24.74 & & & & & \\
\hline
\end{tabular}

The changes were linear for all distances.

power, accounting for sex-related differences in the contribution of aerobic energy to exercise [42,43], a factor that is particularly relevant to longer race distances (i.e. $100 \mathrm{~m}-200 \mathrm{~m})$. It has also been reported that pacing strategy differed between women and men [44]. Men applied a positive pacing strategy whereas women applied a negative pacing strategy in $200 \mathrm{~m}$ and $400 \mathrm{~m}$ medley between 2000 and 2011 for international races [44]. However, it is unlikely that these factors changed significantly during 1994-2011, especially as the change would have had to be greater in Swiss men than in Swiss women to explain the observed results. The gains in swimming speed during the early $21^{\text {st }}$ century following the introduction of new technological swim suits were greater for men than for women in freestyle swimming, while the gains in breaststroke was similar for the two sexes [45]. Although these technological effects might explain the increase in the sex-related difference in Swiss freestyle swimmers, the explanation is countered by the lack of a concomitant increase in FINA swimmers. Differential access to competitive swimming and/or improved training concepts might partly explain the increasing sex-related difference in Swiss freestyle swimming. However, participation in Swiss swimming competition showed a steady annual increase of $3 \%$ by both sexes, during 1994-2011 [46].

The stable sex difference at international level is in agreement with previous investigations $[4,6,26]$. In this

Table 6 Comparison of linear and non-linear regression analysis of changes in sex difference for freestyle and breaststroke swimmers at international level across years to determine which model is the best

\begin{tabular}{|c|c|c|c|c|c|c|c|c|c|}
\hline & $\begin{array}{l}\text { Kind of } \\
\text { regression }\end{array}$ & $\begin{array}{l}\text { Sum of } \\
\text { Squares }\end{array}$ & DOF & AICC & $\begin{array}{l}\text { Best regression } \\
\text { AIC-Test }\end{array}$ & $\begin{array}{l}\text { Best regression } \\
\text { F-Test }\end{array}$ & Delta & Probability & Likelihood \\
\hline $50 \mathrm{~m}$ breaststroke & polynomial & 0.037 & 1 & 17.53 & linear & linear & 23.80 & $6.75 e^{-6}$ & $99.99 \%$ \\
\hline FINA finalists & linear & 1.27 & 4 & -6.26 & & & & & \\
\hline $100 \mathrm{~m}$ breaststroke & polynomial & 0.17 & 2 & 9.28 & linear & linear & 15.80 & 0.00036 & $99.96 \%$ \\
\hline FINA finalists & linear & 2.53 & 6 & -6.51 & & & & & \\
\hline $200 \mathrm{~m}$ breaststroke & polynomial & 0.21 & 3 & -7.73 & linear & linear & 3.24 & 0.16 & $83.5 \%$ \\
\hline FINA finalists & linear & 1.45 & 6 & -10.98 & & & & & \\
\hline $50 \mathrm{~m}$ freestyle & polynomial & 0.16 & 2 & 9.13 & linear & linear & 20.57 & $3.41 e^{-5}$ & $99.99 \%$ \\
\hline FINA finalists & linear & 1.37 & 6 & -11.44 & & & & & \\
\hline 100 m freestyle & polynomial & 0.56 & 0 & -7.19 & linear & undetermined & 3.61 & 0.14 & $85.9 \%$ \\
\hline FINA finalists & linear & 1.48 & 6 & -10.81 & & & & & \\
\hline $200 \mathrm{~m}$ freestyle & polynomial & 0.60 & 0 & -6.60 & linear & undetermined & 6.38 & 0.039 & $96.1 \%$ \\
\hline FINA finalists & linear & 1.13 & 6 & -12.98 & & & & & \\
\hline
\end{tabular}

The changes were all linear. 


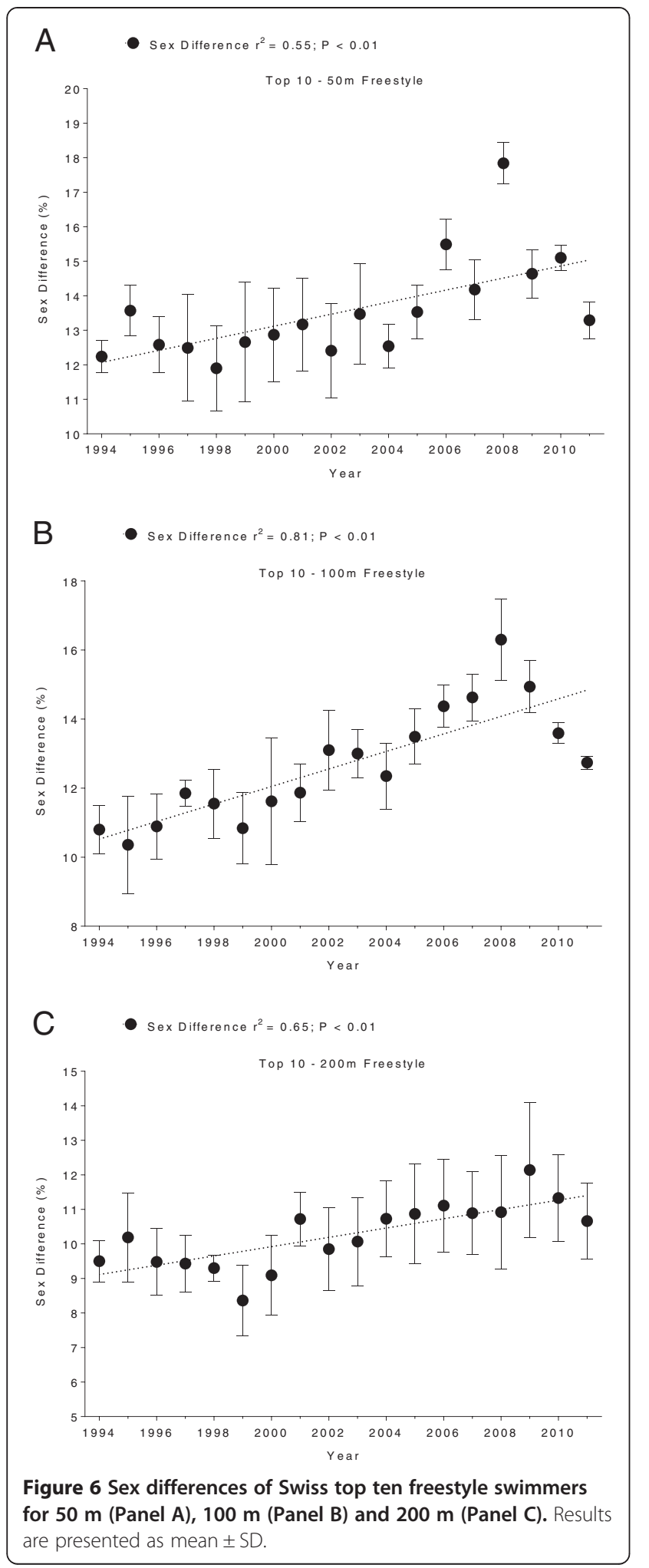

highly competitive and demanding environment both men and women have the same access to state-of-theart training and equipment. It remains to be explored, why at national level men showed a higher increase in

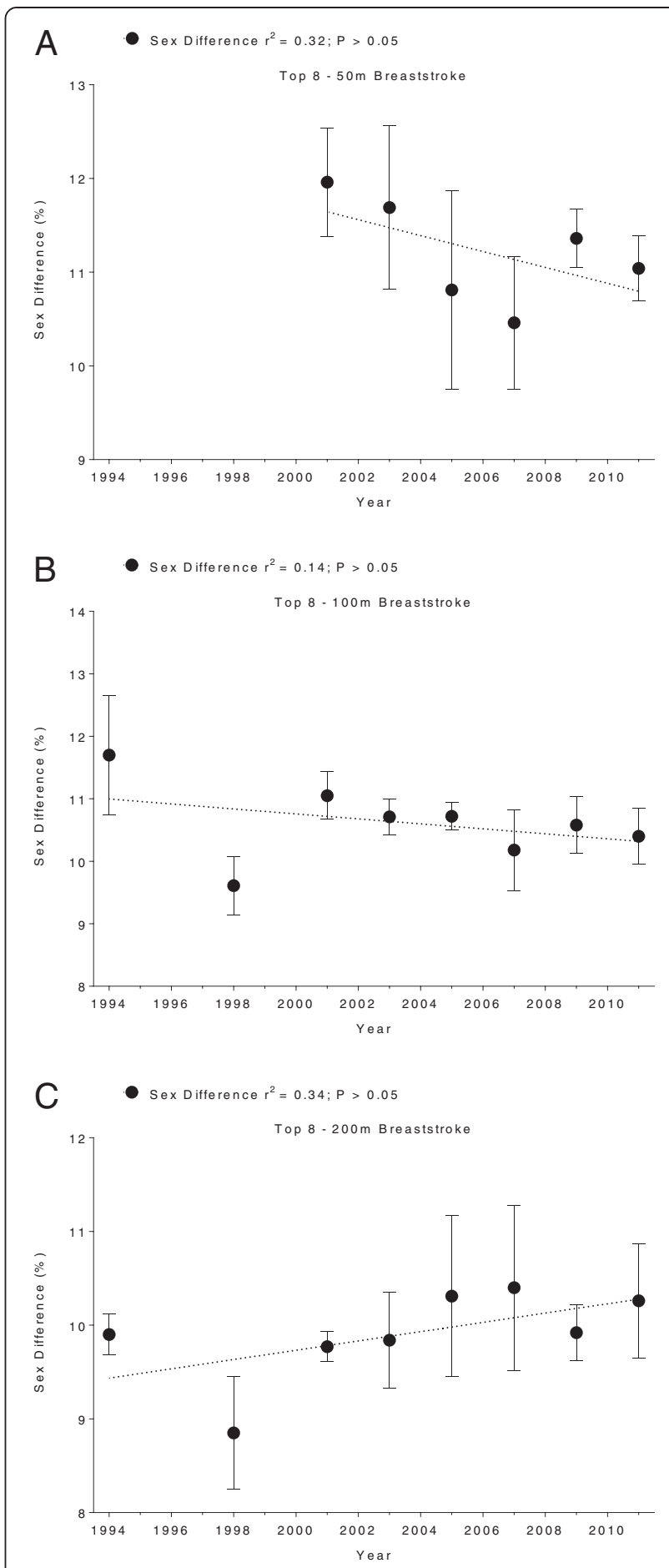

Figure 7 Sex differences of breaststroke FINA finalists for $50 \mathrm{~m}$ (Panel A), $100 \mathrm{~m}$ (Panel B) and $200 \mathrm{~m}$ (Panel C). Results are presented as mean \pm SD.

swim speed compared to women. Although the sex difference in sport is closing, it remains due to biological differences affecting performance. However, the sex difference is also influenced by reduced opportunity and 


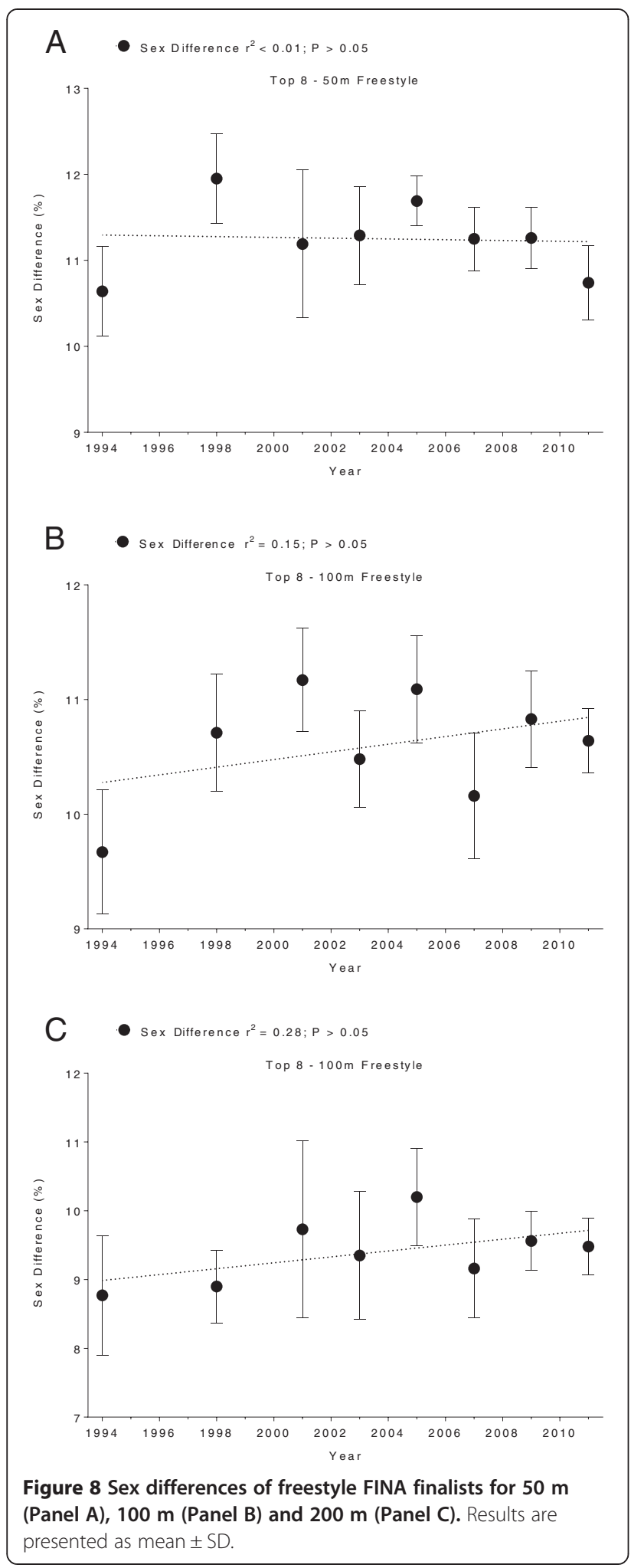

socio-political factors that influence full female participation across a range of sports around the world [47].

There is also indirect evidence that the sex-related difference might be different in breaststroke compared to

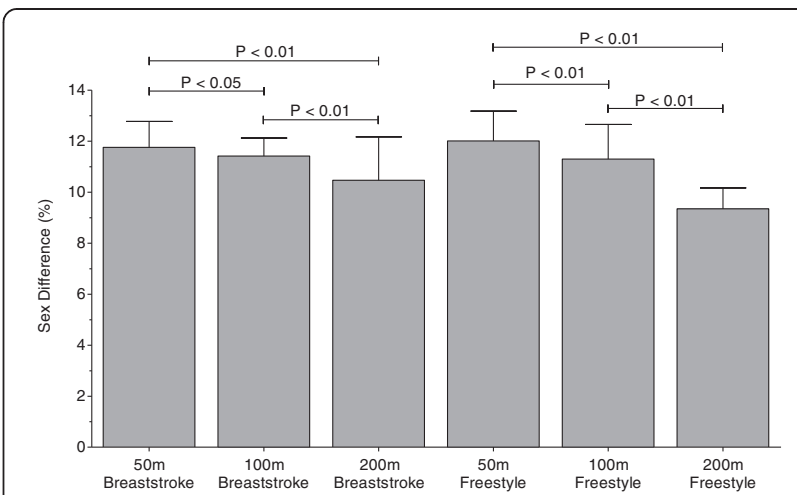

Figure 9 Comparison of sex differences in swimming speeds of the top ten Swiss breaststroke and freestyle swimmers for $\mathbf{5 0} \mathrm{m}, \mathbf{1 0 0} \mathrm{m}$ and $\mathbf{2 0 0} \mathrm{m}$. Results are presented as mean \pm SD

freestyle swimming. Active drag coefficient $\left(C_{d}\right)$ as a measure of technique and performance was lower for faster swimmers [48]. Havriluk found that $C_{d}$ was similar for men and women in freestyle swimming, but that women had a significantly lower $C_{d}$ than men in breaststroke [49]. Therefore, the greater power of men, which allows them to outperform women in freestyle swimming, might not provide such a great advantage in breaststroke.

\section{Sex difference in swimming performance decreased with} increasing distance

The results of the present study showed a decrease in sex-related difference with increasing distance for both breaststroke and freestyle swimming. These results confirm the conclusions of Tanaka and Seals [38] reporting a decrease in the sex-related difference in freestyle performance with increasing race distance from $50 \mathrm{~m}$ to $1,500 \mathrm{~m}$. The decrease was attributed to the fact that women were swimming more efficiently than men, and so show relative improvement in performance as distance increases. The more efficient swimming of women

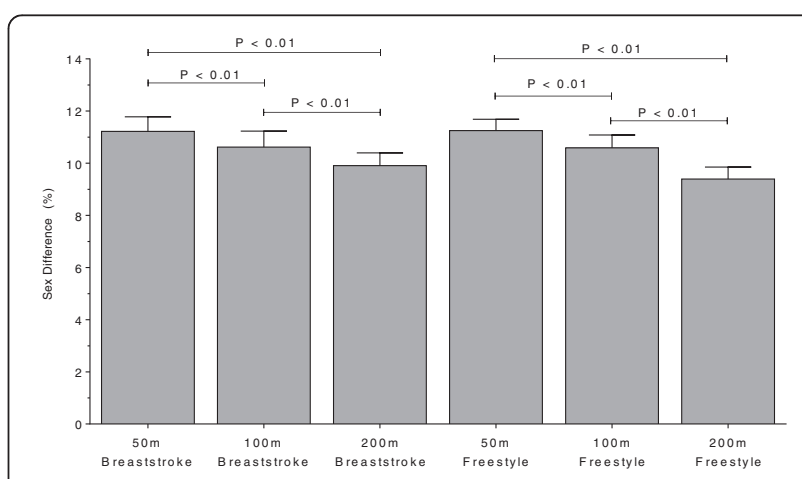

Figure 10 Comparison of sex differences in swimming speeds of FINA finalists in breaststroke and freestyle for $50 \mathrm{~m}, 100 \mathrm{~m}$ and $\mathbf{2 0 0} \mathrm{m}$. Results are presented as mean \pm SD. 
Table 7 Mean speed \pm SD (m/s) of the top breaststroke and freestyle swimmers over 50 m-200 m distances, at FINA and Swiss competitions during the 1994-2011 period

\begin{tabular}{|c|c|c|c|c|}
\hline & \multicolumn{2}{|c|}{ Speed of Swiss swimmers $(\mathrm{m} / \mathrm{s})^{*}$} & \multicolumn{2}{|c|}{ Speed of FINA swimmers $(\mathrm{m} / \mathrm{s}) * *$} \\
\hline & Breaststroke & Freestyle & Breaststroke & Freestyle \\
\hline$\overline{M e n}$ & $1.50 \pm 0.12$ & $1.91 \pm 0.15$ & $1.64 \pm 0.10$ & $2.06 \pm 0.16$ \\
\hline Women & $1.33 \pm 0.09$ & $1.70 \pm 0.11$ & $1.47 \pm 0.10$ & $1.84 \pm 0.13$ \\
\hline
\end{tabular}

All main effects of stroke and sex on swimming speed were highly significant (2-way ANOVA, $p<0.0001$ ). A significant interactive effect of swim style $\mathrm{x}$ sex is indicated by ${ }^{*}(p=0.0001)$ and ${ }^{* *}(p=0.009)$

is due to their greater fat percentage, shorter legs, and smaller body density, resulting in a more horizontal and streamlined position and smaller body size, which reduces body drag $[50,51]$.

Differences in upper body power might also play a role in the decreasing sex-related difference with increasing race distance [52]. It has been shown that swimming performance was associated with dry land strength of the upper body such as mean power of lat pull down back in elite male freestyle swimmers [53]. Freestyle swimming performance was positively correlated with upper body power in races from $50 \mathrm{~m}$ to $400 \mathrm{~m}$ [52], but the correlation weakened with increasing race distance [52]. Thus, the greater muscle power of men might become less important with increasing swim distance [54].

It has been assumed that women would be able to outrun men in ultra-marathon running and it was suggested that the sex difference in running would disappear with increasing running distance particularly in distances longer than the marathon [55]. However, a very recent study investigating the sex differences in ultra-marathon running from $50 \mathrm{~km}$ to $1,000 \mathrm{~km}$ showed that the sex differences in running speeds decreased non-linearly in $50 \mathrm{~km}$ and $100 \mathrm{~km}$ but remained unchanged in $200 \mathrm{~km}$ and $1,000 \mathrm{~km}$ [56]. Furthermore, the sex differences in running speeds showed no change with increasing length of the race distance [56]. The findings suggested that it would very unlikely that women will ever outrun men in ultra-marathons held from $50 \mathrm{~km}$ to $100 \mathrm{~km}$ [56]. For ultra-swimming, however, very recent studies showed that elite female open-water ultra-distance swimmers improved in $10 \mathrm{~km}$ but impaired in $25 \mathrm{~km}$ leading to a linear decrease in sex difference in $10 \mathrm{~km}$ and a linear increase in sex difference in $25 \mathrm{~km}$ [57]. The linear changes in sex differences suggest that women will improve in the near future in $10 \mathrm{~km}$, but not in $25 \mathrm{~km}$ [57]. However, women might be able to beat men in longer ultra-distances. In the $36 \mathrm{~km}$ 'Maratona del Golfo Capri-Napoli' race held from 1954 to 2013, the sex difference in performance decreased linearly from $\sim 38.2 \%$ in 1963 to $\sim 6.0 \%$ in 2013 [58]. The linear change in both race times and sex differences suggested that women might be able to achieve men's performance or even to outperform men in the near future in open-water ultra-distance swimming. Indeed, in the $46 \mathrm{~km}$ 'Manhattan Island Marathon Swim' held in water temperatures $<20^{\circ} \mathrm{C}$ held between 1983 and 2013, the best women were $\sim 12-14 \%$ faster than the best men [59]. Most probably the low water temperatures and the higher body fat enable women to beat men in ultradistance swimming in cold water.

\section{Limitations and implications for future research}

This study has three major limitations. First, we investigated the ten fastest swimmers competing at national level and the eight finalists in the World Championships. The mean of eight swimmers might give a different result compared to the mean of ten swimmers. The $10^{\text {th }}$ fastest woman is not comparable, in terms of level and performance, to the $10^{\text {th }}$ fastest man; this might have influenced the sex difference. Future studies might also normalize the performance (i.e. percent of the best performance of each year) which could actually show a better improvement in women's performance. Second, we used swimming speed as variable to express swimming performance. However, in swimmers, performance could also be compared using FINA points [23]. The 'FINA Points Table' allows comparisons of results among different events. The FINA Points Table assigns point values to swimming performances, more points for world class performances typically 1000 or more and fewer points for slower performances [23]. For future studies, performance could be better compared using the 'FINA Points Table'. Future studies should investigate temporal trends in other swimming styles to determine whether temporal improvement is a generalized phenomenon. Potentially influential factors such as anthropometric characteristics, training, motivation, and nutrition should be included to elucidate the mechanisms underlying temporal changes in athletic performance [16]. Third, we used a time frame of 18 years (1994 to 2011) and investigated the changes across years using linear and non-linear regression analyses. Interestingly, we found only linear changes for both swimming speed and sex difference. In contrast, Nevill et al. [3] and Stanula et al. [9] reported non-linear changes in freestyle swimming speeds. However, Nevill et al. [3] investigated a time period of 50 years (1957-2006) and Stanula et al. [9] of 113 years (1986-2008). The shorter time frame in our 
study most probably explains why we found linear trends and the other authors [3,9] in contrast non-linear trends. The investigation of longer time frames for breaststroke swimmers might show a non-linear trend in both swimming speed and sex difference in swimming speed.

\section{Conclusion}

The results of the present study showed that swimming performance in athletes competing at national and international level improved in freestyle and breaststroke during the 1994-2011 period. The improvement might be related to technological advances, changes in anthropometric and physiological characteristics, improved training methods and competition psychology, improved sports nutrition, and/or increased access to the sport by a larger number of athletes. The sex-related difference in swimming performance did not change significantly over time in breaststroke, or in freestyle swimming by FINA competitors, but increased significantly in Swiss freestyle swimmers. Finally, the sex-related difference in performance declined with increasing race distance in both swim styles.

\section{Competing interests}

The authors declare that they have no competing interests.

\begin{abstract}
Authors' contributions
All authors have been involved in collecting data, writing, drafting and revising the manuscript. MW interpreted the data, drafted and revised the manuscript. CAR carried out the data collection, statistical analysis and interpretation. TR participated in its design and revised the manuscript critically for important intellectual content. RL participated in designing and coordinating the study and revised the manuscript critically. BK conceived, designed, coordinated the study and revised the manuscript. All authors read and approved the final manuscript.
\end{abstract}

\section{Author details}

${ }^{1}$ Institute of General Practice and for Health Services Research, University of Zurich, Zurich, Switzerland. ${ }^{2}$ Cardiovascular Center Cardiology, University Hospital Zürich, Zürich, Switzerland. ${ }^{3}$ INSERM U1093, Faculty of Sport Sciences, University of Burgundy, Dijon, France. ${ }^{4}$ Gesundheitszentrum St. Gallen, Vadianstrasse 26, 9001 St. Gallen, Switzerland.

Received: 13 May 2013 Accepted: 30 April 2014

Published: 9 May 2014

\section{References}

1. Chatterjee S, Chatterjee S: New Lamps for Old: An Exploratory Analysis of Running Times in Olympic Games. App/ Statist 1982, 31:14-22.

2. Cheuvront SN, Carter R, Deruisseau KC, Moffatt RJ: Running performance differences between men and women: an update. Sports Med 2005, 35:1017-1024.

3. Nevill AM, Whyte GP, Holder RL, Peyrebrune M: Are there limits to swimming world records? Int J Sports Med 2007, 28:1012-1017.

4. Schulz R, Curnow C: Peak performance and age among superathletes: track and field, swimming, baseball, tennis, and golf. J Gerontol 1988, 43:P113-120.

5. Whipp BJ, Ward SA: Will women soon outrun men? Nature 1992, 355:25.

6. Seiler S, De Koning JJ, Foster C: The fall and rise of the gender difference in elite anaerobic performance 1952-2006. Med Sci Sports Exerc 2007, 39:534-540.

7. Johnson B, Edmonds W, Jain S, Cavazos J: Analyses of elite swimming performances and their respective between-gender differences over time. J Quant Anal Sports 2009, 5:1-18.
8. FINA, website. http://www.fina.org/H2O/docs/WR_Oct82013.pdf.

9. Stanula A, Maszczyk A, Roczniok R, Pietraszewski P, Ostrowski A, Zając A, Strzała M: The development and prediction of athletic performance in freestyle swimming. J Hum Kinet 2012, 32:97-107.

10. Mytton G, Archer D, Thompson K, Gibson AS: Reliability of retrospective performance data in elite 400-m swimming and 1500-m running. Br J Sports Med 2013, 47(17):e4.

11. Rüst CA, Knechtle B, Rosemann T, Lepers R: The changes in age of peak swim speed for elite male and female Swiss freestyle swimmers between 1994 and 2012. J Sports Sci 2014, 32:248-258.

12. Barbosa TM, Fernandes RJ, Keskinen KL, Vilas-Boas JP: The influence of stroke mechanics into energy cost of elite swimmers. Eur J Appl Physiol 2008, 103:139-149.

13. Barbosa TM, Fernandes $R$, Keskinen $\mathrm{KL}$, Colaço P, Cardoso C, Silva J, Vilas-Boas JP: Evaluation of the energy expenditure in competitive swimming strokes. Int J Sports Med 2006, 27:894-899.

14. Wolfrum M, Knechtle B, Rüst CA, Rosemann T, Lepers R: Sex-related differences and age of peak performance in breaststroke versus freestyle swimming. BMC Sports Sci Med Rehabil 2013, 5:29.

15. Costa MJ, Bragada JA, Mejias JE, Louro H, Marinho DA, Silva AJ, Barbosa TM: Tracking the performance, energetics and biomechanics of international versus national level swimmers during a competitive season. Eur J Appl Physiol 2012, 112:811-820

16. Costa MJ, Bragada JA, Marinho DA, Silva AJ, Barbosa TM: Longitudinal interventions in elite swimming: a systematic review based on energetics, biomechanics, and performance. J Strength Cond Res 2012, 26:2006-2016.

17. Pozo J, Bastien G, Dierick F: Execution time, kinetics, and kinematics of the mae-geri kick: comparison of national and international standard karate athletes. J Sports Sci 2011, 29:1553-1561.

18. Jennings DH, Cormack SJ, Coutts AJ, Aughey RJ: International field hockey players perform more high-speed running than national-level counterparts. J Strength Cond Res 2012, 26:947-952.

19. Seifert L, Leblanc H, Herault R, Komar J, Button C, Chollet D: Inter-individual variability in the upper-lower limb breaststroke coordination. Hum Mov Sci 2011, 30:550-565.

20. Lätt E, Jürimäe T, Mäestu J, Purge P, Rämson R, Haljaste K, Keskinen KL, Rodriguez FA, Jürimäe T: Physiological, biomechanical and anthropometrical predictors of sprint swimming performance in adolescent swimmers. J Sports Sci Med 2010, 9:398-404.

21. Psycharakis SG, Cooke CB, Paradisis GP, O'Hara J, Phillips G: Analysis of selected kinematic and physiological performance determinants during incremental testing in elite swimmers. J Strength Cond Res 2008, 22:951-957.

22. Swiss Swimming Federation. website http://rankings.fsn.ch/.

23. Fédération Internationale de Natation. website http://www.fina.org/.

24. Reinboud W: Linear models can't keep up with sport gender gap. Nature 2004, 432(7014):147.

25. FINA: Report from the FINA Dubai, UAE: Swimwear Approval Commission. 2010:1-12. http://www.fina.org/H2O/docs/misc/Dubai-FINA-BureauSAC_1210_v13d_s-2\%20in1.pdf.

26. O'Connor LM, Vozenilek JA: Is it the athlete or the equipment? An analysis of the top swim performances from 1990 to 2010. J Strength Cond Res 2011, 25:3239-3241.

27. Chatard JC, Wilson B: Effect of fastskin suits on performance, drag, and energy cost of swimming. Med Sci Sports Exerc 2008, 40:1149-1154.

28. Caspersen C, Berthelsen PA, Eik M, Pâkozdi C, Kjendlie PL: Added mass in human swimmers: age and gender differences. J Biomech $\mathrm{s}$, 43(12):2369-2373

29. Issurin VB: New horizons for the methodology and physiology of training periodization. Sports Med 2010, 40:189-206.

30. Psychountaki M, Psychountaki: Competitive worries, sport confidence, and performance ratings for young swimmers. Percept Mot Skills 2000, 91:87.

31. Sheard M, Golby J: Effect of a psychological skills training program on swimming performance and positive psychological development. Int Rev Sport Exerc Psychol 2006, 4:149-169.

32. Stellingwerff T, Maughan RJ, Burke LM: Nutrition for power sports: Middle-distance running, track cycling, rowing, canoeing/kayaking, and swimming. J Sports Sci 2011, 29:S79-S89.

33. Kagawa M: Secular changes in growth among Japanese children over 100 years (1900-2000). Asia Pac J Clin Nutr 2011, 20:180-189. 
34. Charles JD, Bejan A: The evolution of speed, size and shape in modern athletics. J Exp Biol 2009, 212:2419-2425.

35. Chollet D, Pelayo P, Delaplace C, Tourny C, Sidney M: Stroking characteristic variations in the 100-M freestyle for male swimmers of differing skill. Percept Mot Skills 1997, 85:167-177.

36. Seifert L, Chollet D, Chatard JC: Kinematic changes during a 100-m front crawl: effects of performance level and gender. Med Sci Sports Exerc 2007, 39:1784-1793.

37. Smith DJ, Norris SR, Hogg JM: Performance evaluation of swimmers: scientific tools. Sports Med 2002, 32:539-554.

38. Tanaka H, Seals DR: Age and gender interactions in physiological functional capacity: insight from swimming performance. J Appl Physiol 1997, 82:846-851.

39. Zampagni ML, Casino D, Benelli P, Visani A, Marcacci M, De Vito G: Anthropometric and strength variables to predict freestyle performance times in elite master swimmers. J Strength Cond Res 2008, 22:1298-1307.

40. Barbosa TM, Costa MJ, Morais JE, Morouço P, Moreira M, Garrido ND, Marinho DA, Silva AJ: Characterization of speed fluctuation and drag force in young swimmers: A gender comparison. Hum Mov Sci 2013, 32:1214-1225

41. Whyte GP, George K, Sharma S, Firoozi S, Stephens N, Senior R, McKenna WJ: The upper limit of physiological cardiac hypertrophy in elite male and female athletes: the British experience. Eur J Appl Physiol 2004, 92:592-597.

42. Gastin PB: Energy system interaction and relative contribution during maximal exercise. Sports Med 2001, 31:725-741.

43. Maglischo E: Swimming Fastest. Champaign: Human Kinetics; 2003.

44. Saavedra JM, Escalante Y, Garcia-Hermoso A, Arellano R, Navarro F: A 12-year analysis of pacing strategies in 200- and 400-m individual medley in international swimming competitions. J Strength Cond Res 2012, 26:3289-3296.

45. Berthelot G, Len S, Hellard P: Technology \& swimming: 3 steps beyond physiology. Mater Today 2010, 13:46-51

46. SwissSwimming: Jahresbericht 2011. Schweizer Schwimmverband; 2011. http://www.swiss-swimming.ch/desktopdefault.aspx/tabid-612/720_read7404/.

47. Capranica L, Piacentini MF, Halson S, Myburgh KH, Ogasawara E, Millard-Stafford M: The gender gap in sport performance: equity influences equality. Int J Sports Physiol Perform 2013, 8:99-103.

48. Havriluk R: Performance level differences in swimming drag coefficient. Athens: Paper presented at the VIIth IOC Olympic World Congress on Sport Sciences; 2003

49. Havriluk R: Performance level differences in swimming: relative contributions of strength and technique. Oslo: XIth International Symposium for Biomechanics and Medicine in Swimming; 2010.

50. Lavoie JM, Montpetit RR: Applied physiology of swimming. Sports Med 1986, 3(3):165-189.

51. Pendergast DR, Di Prampero PE, Craig AB Jr, Wilson DR, Rennie DW: Quantitative analysis of the front crawl in men and women. J Appl Physiol 1977, 43:475-479.

52. Hawley JA, Williams MM: Relationship between upper body anaerobic power and freestyle swimming performance. Int I Sports Med 1991, 12:1-5.

53. Morouço P, Neiva H, González-Badillo JJ, Garrido N, Marinho DA, Marques MC: Associations between dry land strength and power measurements with swimming performance in elite athletes: a pilot study. J Hum Kinet 2011, 29A:105-112.

54. Gursoy R, Gursoy: Sex differences in relations of muscle power lung function, and reaction time in athletes. Percept Mot Skills 2010, 110:714-720.

55. Bam J, Noakes TD, Juritz J, Dennis SC: Could women outrun men in ultramarathon races? Med Sci Sports Exerc 1997, 29:244-247.

56. Zingg MA, Karner-Rezek K, Rosemann T, Knechtle B, Lepers R, Rüst CA: Will women outrun men in ultra-marathon road races from $50 \mathrm{~km}$ to 1,000 km? Springerplus 2014, 3:97.

57. Zingg MA, Rüst CA, Rosemann T, Lepers R, Knechtle B: Analysis of sex differences in open-water ultra-distance swimming performances in the
FINA World Cup races in $5 \mathrm{~km}, 10 \mathrm{~km}$ and $25 \mathrm{~km}$ from 2000 to 2012. BMC Sports Sci Med Rehabil 2014, 6:7.

58. Rüst $C A$, Lepers $R$, Rosemann $T$, Knechtle B: Will women soon outperform men in open-water ultra-distance swimming in the 'Maratona del Golfo Capri-Napoli'? Springerplus 2014, 3:86

59. Knechtle B, Rosemann $T$, Lepers $R$, Rüst CA: Women outperform men in ultra-distance swimming - The 'Manhattan Island Marathon Swim' from 1983 to 2013. Int I Sports Physiol Perform 2014. Epub ahead of print

doi:10.1186/2052-1847-6-18

Cite this article as: Wolfrum et al:: Changes in breaststroke swimming performances in national and international athletes competing between 1994 and 2011 -a comparison with freestyle swimming performances. BMC Sports Science, Medicine, and Rehabilitation 2014 6:18.

\section{Submit your next manuscript to BioMed Central and take full advantage of:}

- Convenient online submission

- Thorough peer review

- No space constraints or color figure charges

- Immediate publication on acceptance

- Inclusion in PubMed, CAS, Scopus and Google Scholar

- Research which is freely available for redistribution

Submit your manuscript at www.biomedcentral.com/submit
Biomed Central 